\title{
The building of weak expertise: the work of global university rankers
}

\author{
Miguel Antonio $\operatorname{Lim}^{1}$ (D)
}

Published online: 13 April 2017

(C) The Author(s) 2017. This article is an open access publication

\begin{abstract}
University rankers are the subject of much criticism, and yet they remain influential in the field of higher education. Drawing from a two-year field study of university ranking organizations, interviews with key correspondents in the sector, and an analysis of related documents, I introduce the concept of weak expertise. This kind of expertise is the result of a constantly negotiated balance between the relevance, reliability, and robustness of rankers' data and their relationships with their key readers and audiences. Building this expertise entails collecting robust data, presenting it in ways that are relevant to audiences, and engaging with critics. I show how one ranking organization, the Times Higher Education (THE), sought to maintain its legitimacy in the face of opposition from important stakeholders and how it sought to introduce a new "Innovation and Impact" ranking. The paper analyzes the strategies, methods, and particular practices that university rankers undertake to legitimate their knowledge - and is the first work to do so using insights gathered alongside the operations of one of the ranking agencies as well as from the rankings' conference circuit. Rather than assuming that all of these trust-building mechanisms have solidified the hold of the THE over its audience, they can be seen as signs of a constant struggle for influence over a skeptical audience.
\end{abstract}

Keywords University rankings · Experts $\cdot$ Weak expertise $\cdot$ Data $\cdot$ Trust $\cdot$ Credibility $\cdot$ Higher education policy $\cdot$ Times Higher Education

\section{Introduction}

Expertise is among the most important and valued 'commodities' in society. Several cultures of expertise have emerged around the figure of the expert (Holmes and Marcus 2006; Shore et al. 2011; Strathern 2006). Although, as recent political events have shown, their authority is

Miguel Antonio Lim

miguelantonio.lim@manchester.ac.uk

1 The Manchester Institute of Education, The University of Manchester, Oxford Road,

Manchester M13 9PL, UK 
increasingly challenged, those who are recognized as experts usually have their voices heard and wield an array of social, political, and economic power. In this paper I introduce the concept of weak expertise.

Drawing insights from a two-year field study in the sector of university ranking organizations, observations from nine important conferences and fairs on the rankings circuit, eightyfour interviews, and an analysis of hundreds of related documents and news articles, I argue that this kind of deeply contested yet influential expertise can be built in a variety of ways. The constantly negotiated balance between the relevance, reliability, and robustness of university rankers' data and their relationships with their key readers leads to the development and exercise of this kind of expertise.

University rankers are having a real impact in how education is being delivered and how research is being done (Hazelkorn 2007). This is in spite of the critique that many of the organizations and individuals that produce rankings are not recognized as traditionally having formal training or qualifications in education studies. If anything, the trend is also a critique of those who work in higher education. Leon Bolstein, president of Bard College, observes that '(i)t's one of the real black marks on the history of higher education that an entire industry that's supposedly populated by the best minds in the country... is bamboozled by a third rate news magazine ${ }^{1}$, (Bolstein, in Espeland and Sauder 2016).

The influence of rankings in the face of the world's 'best minds' makes their influence even more intriguing. University rankers wield an extraordinary power that some have situated in the wider audit (Power 1997) and neoliberal (Ball and Olmedo 2013) society. Here I show, from the perspective of the rankers, how ranking organizations craft active responses, strategies, and new products, to respond to the needs of universities, as sense-making organizations (Di Maggio and Powell 1983) that are in pursuit of their community's commonly held notions of 'excellence' (Readings 1996).

There is an important gap in this field. The perspective of what rankers do, from the 'inside', is absent. By observing parts of the production of the 2014-2015 THE World University Rankings and events on the international rankings circuit, ${ }^{2}$ I suggest that rankers mobilize two important resources to shore up their credibility: (1) data and (2) their relationships with their audiences. These are brought together by the ranker to construct rankings that are robust, reliable, and relevant. These key elements that underpin rankers' influence in their sector are also the qualities that must be studied in the work of new and emerging experts in other fields.

This article aims to contribute to our understanding of how evaluation instruments affect organizations in the higher education sector, but could be usefully applied to many other organizations which grapple with organizational anxieties (Sauder and Espeland 2009; Fligstein and McAdam 2012). It offers insights into what constitutes expertise. In particular it aims to unpack the strategies, methods, and particular practices that university rankers, as exemplars of weak expertise, undertake to legitimate their knowledge. This explanation requires an approach that includes an insight into the internal life of the university ranker as well as from the ranking events and conferences at which rankers are actually at work.

This paper relates and explains the processes that constitute rankings production as well as the actual strategies by which ranking organizations publicize their products. It builds upon the

\footnotetext{
${ }^{1}$ The newspaper referred to appears to be the US News and World Report (and not the THE).

${ }^{2}$ To put this in perspective, the editor of the THE rankings travels to over 40 ranking events every year (personal communication, 12 September 2014).
} 
knowledge of the reactivity of universities to rankings (Espeland and Sauder 2007) and adds an understanding of a crucially important element: the processes which rankers use to harden the facticity of their ranking knowledge and, as a result, give them a form of expertise in questions around quality in higher education.

Concretely, I show how one ranking organization, the Times Higher Education (THE), sought to maintain its legitimacy in the face of opposition and critique from important stakeholders whom it considered as part of its core readership and target audience. I discuss the THE's decision to develop a standalone ranking separate from its former partner Quacquarelli Symonds (QS). I also present the introduction and development of a new instrument - the ranking of universities by their innovativeness - in which the THE needed to coordinate and solicit the help of its previous data provider, Thomson Reuters, ${ }^{3}$ and its current partner, Elsevier. The THE also asked for feedback from academic advisers as well as the larger public about how to measure the university sector's 'third mission' performance, i.e. making a contribution beyond teaching and research.

Rankers produce their ranking instruments through a process of gathering feedback, engaging with their audiences, and carrying out strategic work to legitimate their instruments. I suggest that rankers produce contested data and need to frequently respond to challenges to their legitimacy. The reason for all this is the need to build trust and credibility, which are the bases of the rankers' claim to expertise and also the root of revenue. Building on this, the concept of weak expertise opens up new questions about the nature and exercise of expertise in higher education and, more widely, in many other spheres where experts actively build and promote their influence.

\section{The rise of metrics in education and the embedded place of university rankings}

When rankings are discussed, there is often great concern over impact (Marginson and Van der Wende 2007). The changes in behavior that rankings bring about - impact - have been studied on the part of many actors. Hazelkorn's (2007) large survey of university managers concludes that rankings are 'here to stay' and that, despite the criticism that rankings receive, people will just have to 'live with them' (Hazelkorn 2008). More than learning to live with rankings, it is becoming more and more important for university managers to play the rankings game well. Governments are also concerned (Lim and Williams Øerberg 2017). In 2008, the European Commission supported an alternative rating system, eventually U-Multirank, in response to the dominance of American and Anglo-Saxon universities in the then THE-QS rankings.

The prominence of rankings in higher education is part of a wider, and longstanding, rise in the importance of indicators and measurements in general society and in the larger field of education. Lawn (2013) explores the 'voyages of measurement' which shows the inexorable rise of metrics, data, and standardization in education throughout the twentieth century. Normand (2010) shows the networked nature of organizations such as the Organisation for Economic Co-operation and Development (OECD) to explain how ideas flow between policymakers and expert communities. Schuller (2005) shows how the prevalent ideas among the OECD epistemic community 'identify and prioritize' issues (Schuller 2005) as well as

\footnotetext{
${ }^{3}$ The THE World University Rankings were produced with data from Thomson Reuters until 2014. The next year's rankings were produced with data from Elsevier.
} 
shape the techniques by which these issues are to be studied and potentially resolved. Politics, 'political work' (Grek 2013), and networking all play a large role in the agenda setting around 'technical work' in education. Networks of academics, policymakers, and experts were all necessary to provide the conditions for the rise of metrics in education.

Normand (2010) suggests that policymakers and leaders have a choice when picking which experts to listen to, but that they often choose those whose opinions closely match their own. In education policymaking, the understanding of the relationships between policymakers and experts exposes some of those choices. I argue that university stakeholders are not powerless in the face of rankings and have the ability to choose the importance of some rankings, or some experts, over others.

The networks of experts and the spaces in which experts meet and socialize are important sites to understand how weak expertise is generated, hardened, challenged, and defended. This account of the THE and other rankers' experimentations and hosting of conferences addresses the need for thicker descriptions of the processes around the production of university rankings.

To begin understanding rankers is to reflect on their operational context. The THE styles itself as the 'global authority on higher education' (Baty 2015). The THE rankings are produced in the context of a newsroom. This sets it apart from other ranking producers. This newsroom is itself part of a larger organization that can be described as an education community platform, TES Global, which is run as a business. However, this context is not static: during the research period it was and continues to be in the process of reorganization which is changing the way the THE goes about its business. This is crucial to understanding both the networks around the THE, its target audiences, its strategic actions, and the potential directions it will take in the future.

\section{Data and the higher education audience}

The World Academic Summit, organized by the THE and hosted by the University of Melbourne in October 2015, had the air of a diplomatic summit rather than an academic meeting. Present were a number of vice chancellors and other university leaders. The venue was the newly built Melbourne School of Design, a visually stunning building at the heart of the university's campus. Organizers recognized it as an ideal place to provide a platform for dialogue among global 'thought leaders' in education. Central to the summit was the launch of the THE 2015 World University Rankings and a rankings 'masterclass' held by THE editorat-large Phil Baty. The attendance of high level university leaders and policymakers is considered one measure of success. At Melbourne, Dirk Van Damme, head of the OECD's Innovation and Measuring Progress (IMEP) division within the Directorate for Education and Skills, spoke about the importance of metrics about teaching in higher education (Van Damme 2015). At this, and its other events, the THE aims to foster conversations about standards-setting at the highest policy levels in education. The desired tone is one of relevance and broad policy impact.

At Melbourne, Baty and a large number of THE staff invited their audience to contribute to what was presented as a work in progress: the evolving THE university rankings. The THE aimed to use the Summit to offer the space in which to reflect upon, gather data for, and ultimately answer some of the issues raised around its own ranking instruments. Baty openly posed questions about the THE's own practices and asked the audience to help the THE make progress. Many of those in Melbourne actively engaged in this reflective practice and appeared to look forward to the next Summit, held at the University of California-Berkeley in 2016. 
Observing ranking summits brings up two important features of university rankings that are relatively understudied: how rankers become experts and what work they carry out in order to produce new, better, and more relevant products. At ranking events, both 'who' and 'how' questions about university rankers can be addressed. By observing the conference circuit it becomes clear which ranking organizations operate in which countries and policy spaces, as well as which individuals work for, manage, and advise them. The circuit also shows how rankers develop material (e.g. brochures and magazines) as well as virtual objects that serve as ranking 'instruments'. These instruments include the many related events that are now a part of the university ranker's growing list of operations.

The growing community of ranking practice that gathers around the annual events organized by university rankers reinforces the need to answer the 'who' question: it appears that a relatively small group of people are having an outsized impact in higher education policy. Although Hazelkorn (2008) and Espeland and Sauder (2007) show the extent of the effects of university rankings on university managers, academics, teachers, and education policymakers, there is not much by way of what the rankers actually do in terms of their community-building efforts. Rankers are not only affecting university leaders 'at a distance', to use a term from governmentality scholars (Foucault 2000); they are actively organizing events and other platforms that serve as spaces for direct dialogue, debate, and sharing of 'best practices' between themselves and university leaders.

\section{Building expertise}

University rankers begin their work by trying to conceptualize 'quality' in higher education. In this task, rankers have to choose both the likely indicators as well as the ways to obtain or generate the relevant data. Choices need to be made regarding the use of certain kinds of inputs: subjective and/or objective. If they use certain kinds of data or propose a certain indicator, they need to have a reasonable and articulated justification for it. In the case of the THE, the use of thirteen indicators was meant to provide a 'balanced and comprehensive' view of excellent performance. This wide range of indicators is not only meant to provide 'balance' but also relevance to political and social concerns.

Rankers are sensitive to national and international policy discussions (Lim and Williams Øerberg 2017). For instance, some policy concerns have recently shifted towards the need for better measurements of teaching quality. In the UK, these include proposals around a teaching excellence framework (HMG 2016) and of other ways to improve the social value and impact of higher education. Rankers have taken up these ideas and set to work on experimenting on the tools and devices that could potentially address these concerns. Ranking organizations such as the THE have begun to expand from the measurement of research towards the measurement of other factors, e.g. innovation. Rankers provide a link between these policy concerns and calculative devices. They can attempt to operationalize ideas that are present in the discussions of the higher education community's 'thought leaders'.

Ranking experts seek to 'translate political concerns into expert languages' (Tan 2014: 306). These concerns could include prevailing government discourses around improving 'value for students' or gaining 'competitiveness in a knowledge economy'. Rankers build new languages around these directives that contribute to the new ways of seeing university quality and behavior. To policymakers and users, experts provide "the techniques needed to fulfill their aspirations" (ibid) as well as the ability to teach them these techniques. The new 
experts then begin to gain the force of legitimacy. They begin to produce facts and their viewpoints are taken up in the outside, real, world.

As ranking devices become more complex, they require increasingly sophisticated data and the corresponding data expertise. Some university ranking outlets began, quite literally, as oneman affairs. Today, however, they involve many more professionals and workers with various tasks and the corresponding skill sets. Rankers are still both surprisingly small-in the sense that a very small number of people make decisions - and surprisingly widespread, when one considers the many auxiliary professionals, associated experts, and targeted audiences that work for and engage with them. Thus the ranking community is now wider and deeper than it was previously.

The network of experts around rankings suggests that 'it takes a village' of regulators, operators, audiences to raise a ranking instrument. Some professionals are entrusted with the verification and dissemination of the data. The production of rankings then expands from the world of the rankings editor and extends to the personnel at the data provider and then on to the various data professionals, visual artists, bibliometricians, those who carry out the reputation survey, the staff at the events team that organizes conferences around rankings, those who manage the rankings website and social media, the academic advisers of the ranking organizations, the media contacts who use rankings as part of their news feeds, and many others.

The ranking space then extends far beyond the physical office of the rankings maker. I argue that it encompasses the various conference sites, even spaces in universities themselves where rankings are studied and incorporated into strategy, insofar as the professionals working in these offices return feedback to the ranking makers. This wide set of actors with their different kinds of expertise comes together to produce the underlying 'science' of assessment. All these actors are linked to the production of the ranking instruments and building of the ranker's expertise.

\section{Data, relevance, and credibility}

Data is of primary importance to the expert. It is the basis on which expertise is built (Grek 2013). Rankers conduct experiments on their data and ask academics to evaluate their work. In this way, rankers develop both new kinds of data and new perspectives on their data. This gives them the potential to extend their expertise. While they take into account the feedback they receive, in the end, rankers decide on their own what data to use, which indicators to include, and what material to publish.

However, for the university ranker, it is not enough to have data. The datasets needs to be processed and they need to be re-presented and made relevant to the THE's various audiences. The process by which the THE treats and gathers its data is the subject of an infographic or special section in every THE rankings issue. There is always some commentary on the THE's methodology as well as commissioned thought-pieces on the rankings' data from technical experts. Conversations about the data are present at every THE-organized summit. Here, the THE aims to get its primary audience in the room and have the most direct conversation as possible with them. Baty explains that their events are 'absolutely for university leaders... mainly presidents and vice presidents, Vice Chancellors of universities, strategic leadership...' (Baty, personal communication, 12 September 2014).

The development of the THE ranking methodology has always aimed to address concerns among its core audience: academics and university managers. Prior to 2010, the THE and QS 
produced a single set of university rankings. Critiques of this joint ranking ranged widely, from technical shortcomings (Bougnol and Dulá 2014), to anchoring effects that favored longestablished universities (Bowman and Bastedo 2011), to audience mis-targeting (Cremonini et al. 2008), among others. Baty and Anne Mroz, then editor of the THE, felt that if academics and high-level administrators were unhappy with the rankings, this could potentially result in difficulties with the circulation and thus the revenues of the magazine.

In 2009 the THE decided to split from the QS due to the growing critical reaction from its readership. The THE says it held a wide consultation over the production of its new go-italone rankings. In creating its own distinct rankings separate from QS, the THE claims it undertook 'the largest consultation exercise ever undertaken to produce world university rankings' (Baty 2010a). This consultation involved 'more than 50 senior figures across every continent', 'more than 250 pages of commentary', and 'more than 300 postings on our website' (ibid) from the wider university community. The idea was to present an open and transparent process in order to produce better rankings relative to the earlier joint version. The sense of being open to changes, and to experimenting with new and better ways to measure university excellence, was important. Trying to have a consultation with its core audience was something that the THE felt to be a strategic activity. There were important commercial reasons to develop new datasets and new models distinct from the previous 'mistrusted' methodology.

"There's no question that at the very beginning, the first task was to restore credibility with our core audience who are academics and senior administrators. We had to give them something that they felt more comfortable with. If the Vice Chancellor or President rings Times Higher Education telling you that your ranking's silly, we have a credibility problem because we need them to trust us and see what we do is responsible. So I think our first audience is definitely senior administration, senior academics." (Baty, personal communication, 9 December 2014)

In order to distance the new standalone THE ranking from the previous one and show how the new rankings improved upon the perceived flaws of the old, Baty 'confessed' to the sins of the past instrument. 'The rankings of the world's top universities that my magazine has been publishing for the past six years, and which have attracted enormous global attention, are not good enough.' (Baty 2010b) Among the deficiencies that the THE highlighted was the large weight of the subjective reputation survey and that the citation metrics as well as other research-oriented metrics were better suited to capture research production in the sciences over the arts and humanities (Mroz 2009).

"Two main flaws in the current rankings were identified: the survey of academic opinion that makes up 40 per cent of the overall score in our rankings was deemed too small this year it was based on fewer than 4,000 responses from around the world, which when aggregated with previous years' results produces a total of 9,386; the other concern was about our use of paper citations to measure research quality.” (Mroz 2009)

But what is more important than the technical methodological change is the way that the THE described the process by which they strengthened their rankings. The process of identifying flaws, trying out better metrics by iteration, and appealing to core audiences for legitimacy were actions seeking to refine expert claims. The THE editors highlighted the involvement of other experts in the process. At the point when they separated from QS, they took on Thomson Reuters as their new data partner. Reuters' data analysts would be brought in 
to strengthen the instrument. The THE showed that they together with these new experts would be involved in building the THE's own knowledge base.

“...we will work with our new data partner, Thomson Reuters, to produce a more rigorous and transparent ranking for 2010 and beyond. We will seek further advice from our editorial board and solicit the views of international rankings experts and our readers to develop a suitable methodology for the sector. And this week, Phil Baty, deputy editor of Times Higher Education and editor of the rankings, met experts in Shanghai at the Third International Conference on World-Class Universities to discuss the way forward." (Mroz 2009)

The changes that the THE introduced were not only defensive changes. They did not only change the indicators that received the most criticism, such as the perceived overweighting of the reputation survey or the skewness of the citation metrics towards the hard sciences. The goit-alone THE rankings also introduced new indicators, such as an innovation indicator, to reflect the concerns of its audience. The goal was not only to correct flaws but also to increase its own relevance. The experiments around these methodological changes needed to yield results that corresponded to commonsensical outcomes that were worthy of the higher education community's trust. For instance, there was a common 'feeling' that Ivy League universities should end up somewhere close to the top of the table, as this was held to be 'common sense'.

I suggest that it is vitally important for experts to have robust data. However, this data needs to be made relevant and built into the discussions in communities of practice. Data and relationships are the two resources that rankers jointly use: they involve their audiences in gathering and strengthening the datasets that they gather and produce in order to arrive at products that are seen as robust, reliable, and relevant. One of the ways that rankers develop their data and their relationships is through experimenting with different kinds of indicators as well as representations and tables that their audiences accept and value. University rankers carefully consider what kinds of data and indicators are relevant to higher education stakeholders and enter into a dialogue as to what kinds of data are robust (Baty, personal communication, 12 September 2014).

This kind of gradual 'assemblage' of calculative ideas and devices is the foundation on which expertise is built (Tan 2014). University rankers gathered their own datasets and developed different instruments suited to different audiences. The differences among the ranking instruments, such as the different methodologies, aimed to capture different qualities of higher education excellence.

Different rankings are oriented to different audiences over which these rankers want to exercise a certain expertise. The QS rankings, for instance, can generally be described as more (international) student-oriented. The Leiden university rankings are oriented towards readers who are more concerned with research performance measured by bibliometric output. The differences between rankers, their audiences, and the various professionals that support them point to the networked nature of the industry of rankings. In the world of rankings, there are multiple actors, multiple sites, and multiple experts.

However, the general trend that binds the rankers together is that all universities have stakeholders who are interested in the excellent performance of their institutions. Rankings have become the mechanism by which the organizational ritual (Powell and DiMaggio 2012) of excellence is more commonly understood and measured. This, in turn, has led to the establishment of 'research and/or reputation management' units within the universities - new 
institutional forms (Meyer and Rowan 1977; Fligstein 2001) that have spread throughout the sector as legitimate agents of excellence and accountability - that gather data for and deal directly with the ranking agencies.

\section{Expertise and experiments: the THE and innovative universities}

The THE, along with others, is currently aiming to build expertise in measuring the performance of the universities' 'third mission', i.e. beyond teaching and research. As part of this goal, it wants to be able to measure universities' innovativeness. One way that the THE understands innovation is as the ability to produce socially relevant processes or products that are, in turn, measured by the number of patents or by the commercial success of these outputs. Baty claims that universities wanted better ways of understanding and being able to compare their abilities to transfer and apply knowledge to society in general and industry in particular.

"We had a public debate and a meeting. We asked for people's feedback. We've got some feedback. We've focused on some ideas, we'll share those ideas to a smaller group of people and ask, 'is this looking sensible to you?' [We'll] get together some consensus around the importance of which metrics are the most important, and how they will be weighted.” (Baty, personal communication, 9 December 2014)

The THE held an open forum on its plan to measure research impact and innovation. The consultation was held on 28 April 2014 in Miami, Florida, USA, at its inaugural THE Young Universities Summit. Several vice chancellors were invited to speak on a panel session. They were selected from six different countries to represent a wide range of national and policy contexts and policymakers from the European Commission. In August 2015, the THE published an article about the most innovative universities using four innovation criteria (Bothwell 2015). It was not exactly a ranking but was "designed to start a conversation" (ibid) about universities and their innovativeness. The THE was explicit about its desire for feedback, asking: 'What other indicators might we develop, how might they be combined and could we work towards a full innovation and impact university ranking?' (ibid). In an interview, the THE rankings editor explained his approach:

"I'm completely of the view that more rankings are better. There's no single correct ranking. And ranking world-class research universities needs one methodology, teaching universities need another ranking, a ranking of social mobility institutions needs another ranking and the third mission needs another. So I am very keen to create the Times Higher, sort of Innovation and Impact ranking.

But that will be an entirely new, separate publication within the portfolio of rankings... Here's another ranking based entirely on how much economic or social impact a university has. So we did have an event in Miami where we introduced this idea. We wrote a news story saying 'we're trying to do this, we want to do this'. We had a consultation around what the ideas would be. And that is going to be followed up with a white paper that Thomson Reuters will produce, where we say, 'Okay, here are the ideas, here's what we're thinking.' And that will be put out for more consultation-give us your views, which ones work, which ones don't work. We've left the production of the white paper to them, because they are the data owners." (Baty, personal communication, 20 August 2014) 
The point on data ownership eventually proved to be a critical one. Although Reuters' data was the foundation of the industry-income-innovation indicator used in the THE World University Rankings until 2014, in the end, Thomson Reuters produced its own rankings. In 2015, Thomson Reuters released its Innovative Universities ranking, in which it "set out to find and rank the world's top 100 innovative universities empirically, building a methodology that employs 10 different metrics" (Thomson Reuters 2015b). Their emphasis on the reach of their data led them to boast about reaching the 'essence' of university innovation and identifying 'reliably' impactful institutions (see Fig. 1).

Thomson Reuters had long gathered patent and other industry-related data, which allowed it to continue thinking about ways to measure, or approximate, how innovative universities were in relation to their peers. The data company used its experience in ranking companies - it had previously compiled industry data and published a report on the world's most innovative companies (Thomson Reuters 2014) — and applied these approaches to the higher education sector. The Reuters' ranking focused on the data that was available or linked to academic papers and drew on data compiled by the Intellectual Property \& Science business of Thomson Reuters. Reuters made clear that their ranking used their own proprietary data and analysis tools. The Thomson Reuters sister companies that provided this data included the Thomson Reuters Intellectual Property \& Science and several of its research platforms, including InCites, the Web of Science Core Collection, Derwent Innovations Index, Derwent World Patents Index, and the Patents Citation Index. In Table 1, I catalog how each of these Thomson Reuters units contributed data that were utilized in each indicator of their innovative universities ranking.

The THE could not produce an innovation ranking comparable to Thomson Reuters' product, because it did not own the data. It decided to shift to another data provider, Elsevier, in 2015, and produced its own innovative university rankings based on the information it received from its new data partner. These rankings were based on four 'innovation indicators'

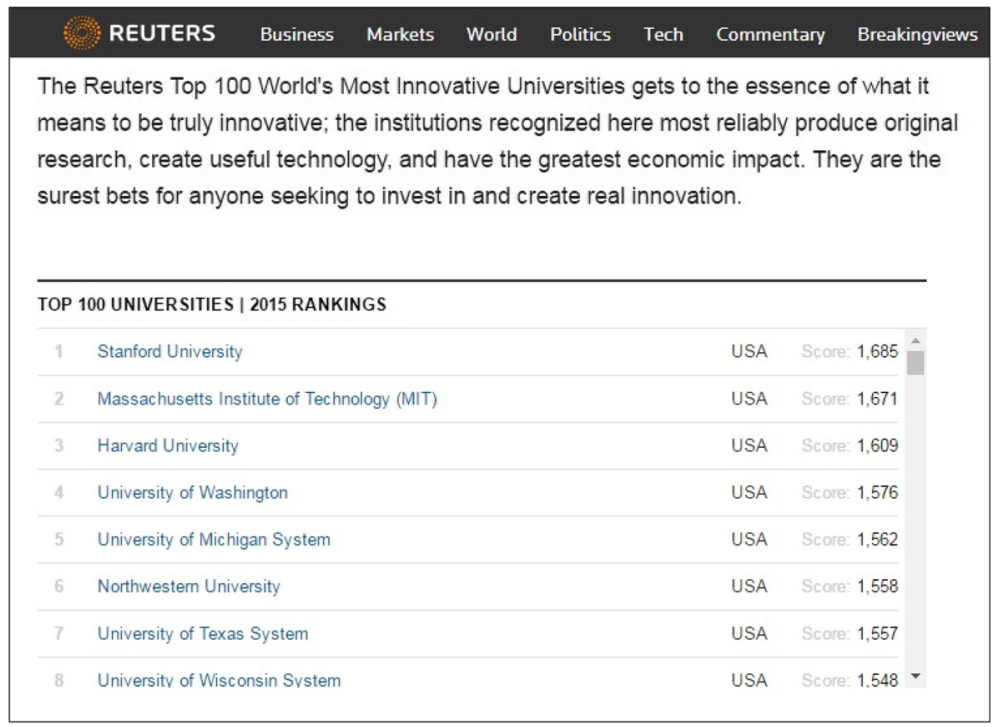

Fig. 1 Screenshot of Reuters' Top 100 Most Innovative Universities (2015). Source: Thomson Reuters 2015 b. Retrieved from: http://www.reuters.com/article/idUSL1N11K16Q20150915 
Table 1 Data sources for Thomson Reuters Innovative Universities ranking

\begin{tabular}{lllll}
\hline & $\begin{array}{l}\text { Derwent } \\
\text { World } \\
\text { Patents Index }\end{array}$ & $\begin{array}{l}\text { Derwent } \\
\text { Innovations } \\
\text { Index }\end{array}$ & $\begin{array}{l}\text { Patents } \\
\text { Citation } \\
\text { Index }\end{array}$ & $\begin{array}{l}\text { Web of Science } \\
\text { Core } \\
\text { Collection }\end{array}$ \\
\hline Patent volume & $\mathrm{X}$ & $\mathrm{X}$ & & \\
Patent success & $\mathrm{X}$ & $\mathrm{X}$ & & \\
Global patents & $\mathrm{X}$ & $\mathrm{X}$ & $\mathrm{X}$ & \\
Patent citations & & & $\mathrm{X}$ & \\
$\begin{array}{l}\text { Patent citation impact } \\
\text { Percentage of patents cited }\end{array}$ & & $\mathrm{X}$ & $\mathrm{X}$ \\
Patent to article citation impact & $\mathrm{X}$ & $\mathrm{X}$ & $\mathrm{X}$ \\
$\begin{array}{l}\text { Industry article citation impact } \\
\text { Total Web of Science Core Collection papers }\end{array}$ & & & & $\mathrm{X}$ \\
\hline
\end{tabular}

Note: Table is the author's schematic adaptation of the data sources of the indicators used in the Thomson Reuters Most Innovative Universities (Thomson Reuters 2015a)

that the THE used in its World University Rankings. These were: (1) resources from industry, (2) industry collaboration based on papers published with an industry partner, (3) patent citations and (4) proportion of industry contribution to the university's overall income. The Elsevier database seems less comprehensive with regard to industry and patents than Thomson Reuters; nevertheless, the THE presented some of their new datasets in ways that would be interesting and relevant to university leaders. The THE showed, for example, a comparison of industry income generated on average by each academic in a range of countries. They then extended this analysis to individual universities in order to rank them (Fig. 2).

Baty did not think that a new ranking around innovation would, in itself, be a commercial success for the THE, but thought that it was important to widen the range of data products that the THE already offered. In the face of other organizations developing other data sets and other rankings - including innovation rankings - it was important that the THE maintain its expertise in that same space as well as in other aspects of university third mission activities.

"I don't think it's going to be a massive commercial panacea. But for me, it's just another good quality editorial product. It's responsible in the field of rankings, because it's saying there's no single model of excellence but different types of excellence, different types of mission, recognized in different ways. So I think it's going to be just one of the expanding range of data sets we put out. Of course, every new data set brings us a new traffic, new audience, new coverage in the media. They can be commercialized in that simple way of a publication with advertising or what have you." (Baty, personal communication, 20 August 2014)

Control over the data to produce these different rankings was very important. As I have shown, although Baty wondered whether innovation rankings would themselves be a commercial success, it was important to have the ability to produce new kinds of rankings that could then become potential revenue streams. These new rankings would depend on new datasets. In the case described above, the THE was inventive in generating its own innovation ranking despite changing data providers and in the face of its old partner Thomson Reuters developing their own similar ranking.

Up until 2014, there continued to be limited internal capacity on the THE's part to understand the data behind the rankings they published. Within the THE, there were no 
Average industry income per academic by country

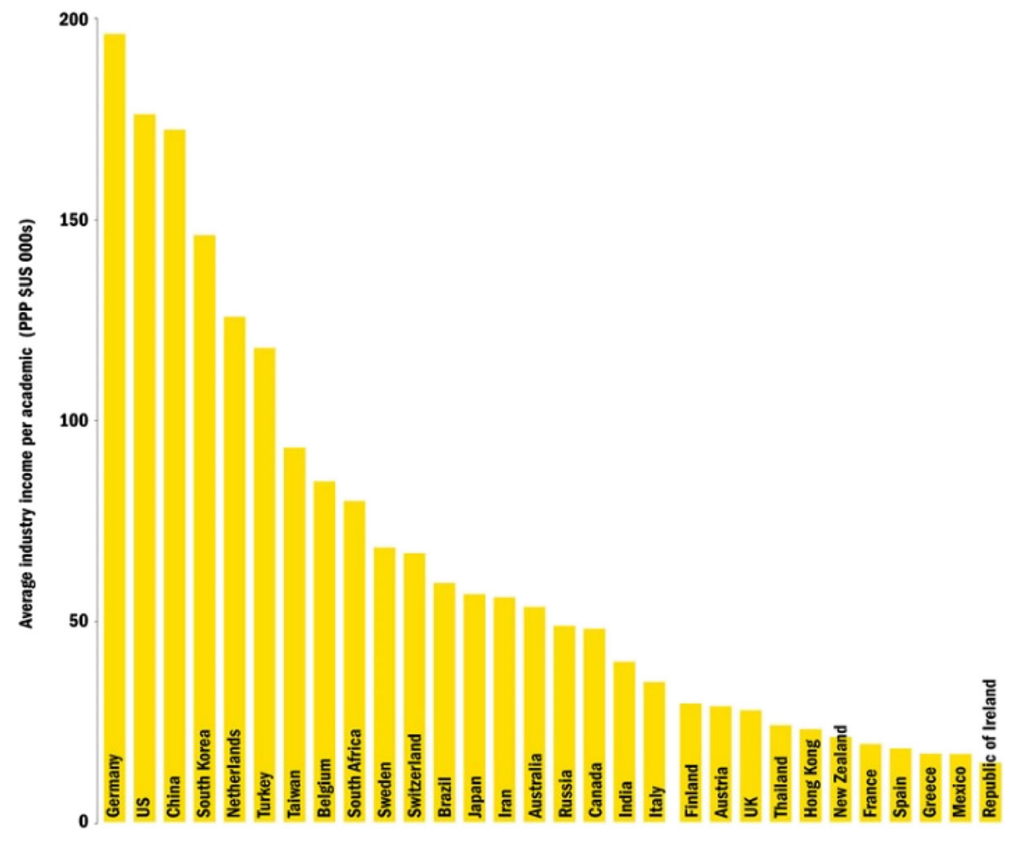

Fig. 2 Average industry income per academic per country. Source: Bothwell and Staufenberg (2016), The world's top universities for attracting industry funding (3 March 2016), Times Higher Education. Retrieved from https:/www.timeshighereducation.com/world-university-rankings/funding-for-innovation-ranking-2016

ranking data analysts, professional bibliometricians, or statisticians hired directly to work on the rankings. These were left to data analysts working with the THE's partners, such as Thomson Reuters. Because the integrity of data and its correct interpretation and presentation were crucial to cementing the THE's claims of expertise in providing a useful aid to thought leaders in the sector, the THE decided to invest in building its data collection and analysis team. This process continues and Baty described this ongoing change as 'the largest investment in [THE's] history' (Baty, personal communication, 15 April 2015).

The THE investment in building its data-building capacity was meant to secure the 'sustainability' of its rankings and the business model around it (ibid). Building its own data team meant that the THE could collect new forms of data, allowing it to produce other rankings based on a different mix of indicators as well as undertake in-house comparative data analyses of universities. This model underlies the THE's claims to expertise. As the THE transforms into a data company itself, it is seeking to guarantee one of the key sources of its expertise even as it maintains and strengthens its ability to make data relevant to its community.

\section{'Trust is everything'}

Credibility and relevance are both crucially important to the THE. It is not only a matter of its standing in the higher education community. To the extent that it is successful, the THE is able to convert credibility and relevance into material resources and a revenue stream. The magazine has a core audience; it claims it is meant specifically for higher education 
professionals and researchers. Yet it also has a wider audience. Many other kinds of readers, such as students, parents, and the wider public, are interested in the THE World University Rankings as well as its other regional and reputation-only-based rankings. The magazine needs its expertise to be recognized by these various audiences.

In order to sell its magazine, the THE needs to be trusted. The THE's subscription and advertising space model works on the basis of its relationship with its readership. Its audiences need to be convinced of the value of the magazine to buy the magazine issues and to advertise in its pages. For the THE to profitably organize its conferences, it needs its expertise to be recognized. At its conferences, commercial exhibitors need to be convinced that the THE's expertise will draw the right kind of thought leaders to attend.

Baty stresses that 'for a newspaper trust is everything' (Baty, personal communication, 9 December 2014). Trust was 'everything' for the THE because it maintained the value of the newspaper and its judgment in the eyes of its targeted readership and community. Different mechanisms were and continue to be used to build that trust. These include the summits, Baty's many field trips, and the THE's many online media platforms in which Baty and the organization dialogues with their different audiences. Through these various platforms, Baty and the THE have the chance to explain ranking developments including potential changes in methods for gathering data, the reason for various methodological choices, and why they gave certain weights to certain characteristics. These discussions are all meant to be transparent and open and to give audiences a potential stake in building the ranking instrument. The list of trust-building strategies is a long one because, despite the many efforts on the part of rankers, some among its audience remain deeply skeptical.

\section{Concluding remarks}

In this paper I argue that ranking organizations build their expertise using a variety of strategies. These include the use of 'hard' data such as bibliometrics and interaction with various stakeholders - university leaders, other data experts, and even students. The first involves the gathering, compilation, and delivery of 'robust' data on higher education. The second entails various processes of building a community of users, of an audience, that places its trust in the ranker and who considers its expertise relevant to real problems. These are at least two of the components that form the basis of the expertise that global rankers seek to build. This paper contributes important insight into this process, because there is a gap in the understanding of how the influence of rankers as 'new experts' takes place from the perspective of the rankers' own activities.

Throughout the paper, using sources both within and outside the ranking organizations, I have outlined the ways in which the THE has expanded its network of both data professionals and workers in order to build the capacity to gather data, to test data, and to develop changes. Other workers have taken up other roles - e.g. acting as interlocutors with their audiences, organizing platforms for dialogue among higher education thought leaders, and gathering feedback about their own instruments.

The overall structure upon which rankers carry out their expertise-building strategy is widespread, but can be experienced more readily in a ranking 'moment' such as the World Academic Summit at which many of those who are members of the ranking community are present. These conferences matter because rankers do not become experts in the field on their own. Rather, they engage in many activities that are brought about by a need to win over a certain complicit consent from their audiences. 
There are many reasons why organizations seek external validation, but one of the most important is the need to be seen as an excellent university or at least on the road to excellence. Universities are in the grip of a powerful reputational 'iron cage' (Di Maggio and Powell 1983) in a sector increasingly subject to comparison. However, by presenting the strategies used by university rankers, I also want to suggest that higher education leaders have the capacity to reflect, resist, and, importantly, shape the metrics by which they accept to be 'judged'. Rankers are only weak experts in that they constantly need to strengthen their expertise through a sustained engagement with their principal audiences.

Rather than assuming that all of the trust-building mechanisms have solidified the hold of the THE over its audience, they can be seen as signs of a constant struggle for trust and credibility among a skeptical audience. Nevertheless, the THE and other ranking organizations do indeed have policy effects. The THE's claim to be the global authority in higher education seems a vastly ambitious one but it does not detract from its actual influence (Hazelkorn 2008).

However influential they may be, rankers are only weak experts. The weakness of the ranker's expertise is one of the reasons behind the investments in data-gathering at the THE and the growing refinements in data treatment among the other rankers. Although they are still subject to much criticism, rankers have had to change their methods in order to make them, in the eyes of their audiences, more robust. The various feedback mechanisms - including social media and conferences - are ways that rankers such as the THE maintain a conversation with users but also critics. They are signs not necessarily of strength but of a constant need to keep the academic community on board.

Rankers never achieve a full and unquestioned grasp of their data; their audiences are continually bringing up various critiques. The spaces (e.g. conferences) and processes (e.g. refining methodologies) of trying to harden data and getting audiences to accept their methods shows, on the one hand, the weakness of rankers' expertise, but on the other, a real engagement and influence in the higher education community. Here I have shown how the THE aimed to shore up its own datasets as well as obtain an active, trust-building engagement with its audience to make good on its ambitious claim of being the 'global authority on higher education' (Baty 2015). The need to make this claim is a sign of both weakness and expertise.

Acknowledgements This work was supported by the European Commission FP7 People programme: Marie Curie Initial Training Network UNIKE (Universities in Knowledge Economies) under Grant Agreement number 317452.

Open Access This article is distributed under the terms of the Creative Commons Attribution 4.0 International License (http://creativecommons.org/licenses/by/4.0/), which permits unrestricted use, distribution, and reproduction in any medium, provided you give appropriate credit to the original author(s) and the source, provide a link to the Creative Commons license, and indicate if changes were made.

\section{References}

Ball, S. J., \& Olmedo, A. (2013). Care of the self, resistance and subjectivity under neoliberal governmentalities. Critical Studies in Education, 54(1), 85-96.

Baty, P. (2010a). World university rankings subject tables: robust, transparent and sophisticated. Retrieved from: https://www.timeshighereducation.co.uk/world-university-rankings/2010-11/worldranking/analysis/methodology. Accessed 2 Sept 2015.

Baty, P. (2010b). Views: ranking confession. Inside Higher Ed. Retrieved from: https:/www.insidehighered. com/views/2010/03/15/baty. Accessed 9 Nov 2015.

Baty, P. (2015). Times higher education rankings masterclass. Moscow. Lecture.

Bolstein (undated) in Espeland, W. N., \& Sauder, M. (2016). Engines of anxiety: Academic rankings, reputation, and accountability. Russell Sage Foundation. 
Bothwell, E. (2015). Which universities are the most innovative? Times Higher Education. Available at: https://www. timeshighereducation.com/features/which-universities-are-the-most-innovative. Accessed 15 Dec 2015.

Bothwell, E., \& Staufenberg J. (2016). The world's top universities for attracting industry funding. Times Higher Education. Retrieved from: https:/www.timeshighereducation.com/world-university-rankings/funding-forinnovation-ranking-2016. Accessed 30 July 2016.

Bougnol, M. L., \& Dulá, J. H. (2014). Technical pitfalls in university rankings. Higher Education, 69(5), $859-866$.

Bowman, N. A., \& Bastedo, M. N. (2011). Anchoring effects in world university rankings: Exploring biases in reputation scores. Higher Education, 61(4), 431-444.

Cremonini, L., Westerheijden, D., \& Enders, J. (2008). Disseminating the right information to the right audience: Cultural determinants in the use (and misuse) of rankings. Higher Education, 55(3), 373-385.

Di Maggio, P., \& Powell, W. W. (1983). The iron cage revisited: Collective rationality and institutional isomorphism in organizational fields. American Sociological Review, 48(2), 147-160.

Espeland, W. N., \& Sauder, M. (2007). Rankings and reactivity: How public measures recreate social worlds. American Journal of Sociology, 113(1), 1-40.

Fligstein, N. (2001). Social skill and the theory of fields. Sociological Theory, 19(2), 105-125.

Fligstein, N., \& McAdam, D. (2012). A theory of fields. Oxford University Press.

Foucault, M. (2000). Ethics: subjectivity and truth: the essential works of Michael Foucault, 1954-1984 (vol. 1). In P. Rabinow (Ed.). London: Penguin.

Grek, S. (2013). Expert moves: International comparative testing and the rise of expertocracy. Journal of Education Policy, 28(5), 695-709.

Hazelkorn, E. (2007). How do rankings impact on higher education? OECD Institutional Management in Higher Education. Retrieved from: www.oecd.org/edu/imhe/39802910.pdf. Accessed 25 Sept 2015.

Hazelkorn, E. (2008). Learning to live with league tables and ranking: the experience of institutional leaders. Higher Education Policy, 21, 193-216.

HMG (Her Majesty's Government). 2016. Success as a knowledge economy, cm 9258.

Holmes, D. R., \& Marcus, G. E. (2006). Para-ethnography and the rise of the symbolic analyst. Frontiers of Capital: Ethnographic Reflections on the New Economy (pp. 33-57). Durham: Duke.

Lawn, M. (2013). Voyages of measurement in education in the twentieth century: Experts, tools and centres. European Educational Research Journal, 12(1), 108-119.

Lim, M. A., \& Williams Øerberg, J. (2017). Active instruments: on the use of university rankings in developing national systems of higher education. Policy Reviews in Higher Education, 1(1), 91-108.

Meyer, J. W., \& Rowan, B. (1977). Institutionalized organizations: Formal structure as myth and ceremony. American Journal of Sociology, 83(2), 340-363.

Marginson, S., \& Van der Wende, M. (2007). To rank or to be ranked: The impact of global rankings in higher education. Journal of Studies in International Education, 11(3-4), 306-329.

Mroz, A. (2009). Leader: only the best for the best. Retrieved from: https://www.timeshighereducation.co. uk/comment/leader/leader-only-the-best-for-the-best/408968. article?sectioncode $=26 \&$ storycode $=408968$ $\& c=1$. Accessed 2 Sept 2015.

Normand, R. (2010). Expertise, networks and indicators: the construction of the European strategy in education. European Educational Research Journal, 9(3), 407-421.

Powell, W. W., \& DiMaggio, P. J. (Eds.). (2012). The new institutionalism in organizational analysis. University of Chicago Press.

Power, M. (1997). The audit society: rituals of verification. OUP Oxford.

Readings, B. (1996). The university in ruins. Cambridge: Harvard University Press.

Sauder, M., \& Espeland, W. N. (2009). The discipline of rankings: Tight coupling and organizational change. American Sociological Review, 74(1), 63-82.

Schuller, T. (2005). Constructing international policy research: The role of CERI/OECD. European Educational Research Journal, 4(3), 170-180.

Shore, C., Wright, S., \& Però, D. (Eds.). (2011). Policy worlds: anthropology and the analysis of contemporary power (vol. 14). Berghahn Books.

Strathern, M. (2006). A community of critics? Thoughts on new knowledge. Journal of the Royal Anthropological Institute, 12(1), 191-209.

Tan, Z. S. (2014). The construction of calculative expertise: The integration of corporate governance into investment analyses by sell-side financial analysts. Accounting, Organizations and Society, 39(5), 362-384.

Thomson Reuters. (2014). Thomson Reuters Names the 2014 Top 100 Global Innovators. Retrieved from: http://www.prnewswire.com/news-releases/thomson-reuters-names-the-2014-top-100-global-innovators281728431.html. Accessed 25 July 2016.

Thomson Reuters. (2015a). Methodology: the world's most innovative universities. Retrieved from: http://www. reuters.com/most-innovative-universities/methodology. Accessed 25 July 2016. 
Thomson Reuters. (2015b). The world's most innovative universities. Retrieved from: http://www.reuters. com/article/idUSL1N11K16Q20150915. Accessed 25 July 2016.

Van Damme, D. (2015). Opening the 'black box': assessing teaching and learning excellence as a game changer in higher education. Melbourne: University of Melbourne Keynote speech. 